\title{
OS DESASTRES NO RIO DE JANEIRO: CONCEITOS E DADOS
}

\author{
CÉSAR AUGUSTO MARQUES DA SILVA ${ }^{1}$
}

\begin{abstract}
Resumo
O Estado do Rio de Janeiro passou por profundas transformações nesse início de século, com as perspectivas econômicas da exploração de petróleo e dos grandes eventos esportivos. Ambientalmente, uma série de eventos foram marcantes, como o deslizamento em Angra dos Reis, em 2002 e 2010; do Morro do Bumba, em 2010; da Região Serrana em 2011, e mais recentemente, a escassez hídrica de 2014/2015. Considerando esse cenário, esse artigo traça um perfil de dinâmicas relativas aos desastres segundo diversas fontes de dados, como a Pesquisa de Informações Básicas Municipais e o Atlas Brasileiro de Desastres Naturais. Debatemos conceitualmente a ideia de desastre e analisamos as (in)consistências das bases de dados disponíveis, mostrando que, a despeito da disseminação da presença de órgãos de preparo em relação aos desastres, tais eventos também são dispersos no território fluminense.
\end{abstract}

Palavras-chave: desastres, Rio de Janeiro, base de dados.

\section{Abstract}

In the beginning of this century Rio de Janeiro state have been deeply changed, mostly due to economics perspectives related to off-shore oil exploitation and major sports events. A series of environmental disasters also occurred in this period, such as the landslides in Angra dos Reis, in 2002 and 2010; in Morro do Bumba, in 2010; in the Região Serrana, in 2011; and the water scarcity of 2014/2015. Considering this set of disasters, this article provides a general overview of risks and disasters in Rio de Janeiro according to several data sets, such as Munic (IBGE) and the Brazilian Atlas of Natural Disasters. We debate the concept of disaster and analyze the consistencies of these databases, discussing that, even though there is a spread of existent institutions that should deal with disasters in this territory, there is also a dispersion of disasters.

Keywords: disasters, Rio de Janeiro, database.

\section{INTRODUÇÃO}

O Estado do Rio de Janeiro é formado por 92 municípios divididos em oito regiões de governo, com uma população de 15,99 milhões de pessoas em 2010 (IBGE, 2010). No quadro geral dos desastres no Brasil, a situação do Estado do Rio de Janeiro não é de excepcionalidade. Ao contrário, os deslizamentos e enchentes na Região Serrana do Rio de Janeiro em 2011 (Castilho, Oliveira e Fabriani, 2012), o deslizamento do morro do Bumba em 2010 (sILva, 2012) e os deslizamentos em Angra dos Reis na passagem de 2009 para 2010 (REIS, CORDEIRO e LOPES, 2011) foram exemplos de desastres que trouxeram profundas rupturas sociais e institucionais, com impactos para a dinâmica demográfica e social de tais localidades.

O mapeamento sobre desastres no Brasil feito pela Universidade Federal de Santa Catarina para o período 1991-2012 (2013a; 2013b), com base nos dados da Defesa Civil, denota que na região sudeste e costeira do país os fenômenos mais recorrentes estão relacionados a chuvas intensas, que geram movimentos de massa, inundações e alagamentos. No Rio de Janeiro, o relatório identificou 727 ocorrências de desastres no período, das quais $21,05 \%$ foram movimentos de massa, $34,52 \%$ enxurradas e $26,13 \%$ inundações (UFSC, 2013b). De modo geral, pesquisou-se algum tipo de desastre em $87 \%$ dos munícipios.

1 Sociólogo pela Unicamp, mestre e doutor em Demografia (UnICAMP). Pesquisador e professor do programa de pós-graduação em População, Território e Estatísticas Públicas da ENCE/IBGE. cesar.m.silva@ibge.gov.br. 
Por outro lado, atualmente o problema da escassez também é vislumbrado. A partir de 2014, a falta de água passou a ameaçar crescentemente o abastecimento das principais metrópoles do Estado de São Paulo, ou seja, tanto os eventos extremos de pluviosidade como a estiagem se configuraram como problemas (CARMo et al., 2014). No Rio de Janeiro, as situações de estiagem também são preocupantes. Com $75 \%$ da população do Estado vivendo na Região Metropolitana do Rio de Janeiro, que é abastecido principalmente pelo sistema Guandu (ANA, 2010), a falta de água para abastecimento já surge em alguns contextos.

Partindo dessas duas situações, o artigo explora o conceito de desastres, ampliando-o para incorporar as questões relativas ao estresse hídrico e aos excessos pluviométricos, debatendo especificamente o caso do Rio de Janeiro.

\section{OS DESASTRES NO BRASIL}

As chuvas intensas e secas prolongadas verificadas nas mais diversas regiões do território brasileiro são, ano após ano, noticiadas como eventos extremos que atingem tanto as áreas urbanas como rurais do país. Os efeitos desses fenômenos são por vezes perversos, inibindo que os atingidos possam acessar a recursos de modo eficiente e construir uma resposta efetiva a eles. Entretanto, é necessário ressaltar que os efeitos de chuvas intensas e das estiagens são bastante diferenciados.

Geralmente, o primeiro caso é mais intensamente relacionado ao desastre. Para esses, a maior resposta política no nível federal foi a institucionalização do Centro de Monitoramento e Alertas de Desastres Naturais (Cemanden) ${ }^{2}$. Essa iniciativa demonstra o tratamento geral dado aos desastres no caso brasileiro, com ênfase nas tecnologias de previsão meteorológica e pouca compreensão acerca dos mecanismos que os causam. Ademais, também mostra a relativa confusão entre o que são o fenômeno e o desastre. Se o primeiro tem um maior componente "natural", o segundo é socialmente construído, ou seja, o desastre não é natural. Tais fenômenos são corriqueiros em diversas regiões do país, e atingem rapidamente grandes proporções.

Já os desastres de seca são comumente associados à região Nordeste do país, nos ambientes áridos e semiáridos. Não são eventos que se configuram de modo pontual, mas ao contrário, tomam forma ao longo de meses e anos. As principais bases de dados já incorporam esse tipo de evento como desastre. O EM-DAT ${ }^{3}$ (Emergency Events Database), que agrega informações de desastres em todo o globo, possui informações sobre em uma série de tipologias, entre as quais há o desastre da seca. Do mesmo modo, o Atlas Brasileiro de Desastres Naturais (UFSC, 2013a) também considera a estiagem e a seca como desastres.

Já a Política Nacional de Proteção e Defesa Civil (PNPDEC) (2012), que tem como algumas de suas diretrizes formular ações preventivas relacionadas à minimização dos desastres, prevenir desastres relacionados a corpos d'água e realizar planejamento com base em pesquisas e estudos sobre áreas de risco e incidência de desastres no território nacional, e como um dos objetivos reduzir os riscos de desastres, não trata em nenhum ponto especificamente sobre os desastres de secas e estiagens.

Um dos principais órgãos oriundos de tal política, o Cemaden, também prioriza as questões de risco, deslizamento e alagamentos. Sua atuação é pautada basicamente pela técnica da predição de extremos pluviométricos, com consequente emissão de alertas para as áreas atingidas. Sua ação é, portanto, relacionada a fenômenos do excesso de chuvas, que podem desencadear situações de colapso muito rapidamente ${ }^{4}$. Foi só com o agravamento da crise hídrica do Sudeste que o Cemaden passou a divulgar relatórios públicos sobre a seca e, mesmo assim, de forma limitada. Em 2015, o órgão publicou um relatório específico sobre a dinâmica do Sistema Cantareira, explorando os diversos cenários pluviométricos para a sua possível recuperação ou ainda maior degradação em 2015 (Cemaden, 2015).

No caso dos riscos de deslizamentos e inundações, a prevenção e o monitoramento são certamente importantes, mas outras questões relativas ao que fazer uma vez emitido o alerta também o são.

\footnotetext{
2 Disponível em http://www.cemaden.gov.br. Acesso em 16/12/2014.

3 http://www.emdat.be/

4 Para comprovar a atuação do CEMADEN basta observar as linhas de pesquisa do Centro, disponíveis em http://www.cemaden.gov. br/linhasdepesquisa.php. Acesso em 25/02/2015.
} 
Como e para onde deve ser o deslocamento? Qual modelo de urbanização/desenvolvimento que está na gênese do processo? Tais dimensões não são alvo do órgão e parecem ser de pouca prioridade no nível do Governo Federal, o que também traz rebatimentos às demais escalas de governo.

Desse modo, a produção cartográfica de mapeamentos de risco continua sendo a tônica das pesquisas sobre riscos e desastres, onde geralmente são identificadas áreas de risco com os moradores urbanos mais pobres. Para Valêncio (2012), tais mapeamentos são legitimados pelo aparato técnico do qual estão revestidos e utilizados para perpetuar o trinômio congelar, interditar e remover. Primeiro se invalida o direito dos empobrecidos em firmar lugar, então se destitui suas moradias de quaisquer condições de segurança e, por fim, a remoção é executada, seguida de preferencial destruição do imóvel e construção de outra obra que crie barreiras que impossibilitem sua ocupação futura.

Valêncio (2012) discute que essas ferramentas não seriam nem as respostas nem os instrumentos mais adequados para o entendimento e a governança de fenômenos tão complexos como são os chamados desastres naturais. São, na verdade, parte de uma narrativa institucional que explica os desastres de modo simplista, através da formulação de um falso tripé: de que existe um 'dia do desastre', que esse é um desastre natural, e que a busca pelo retorno à normalidade deve ser perseguida.

Há uma forte tensão na conceituação do desastre, que ocorre em uma arena de disputa. Por um lado, propostas com noções mais técnicas, como a adotada pela UNISDR (UNITED NATIONS INTERNATIONAL STRATEGY FOR DISASTER REDUCTION, 2009), segundo a qual o desastre é uma grave perturbação na sociedade que envolve perdas de grande extensão, sejam elas humanas, materiais ou ambientais, com impactos que excedem sua capacidade em lidar com os prejuízos. No Brasil, a Defesa Civil Nacional (Decreto ${ }^{\circ}{ }^{\circ} 7.257 / 10$ ), define-os como o resultado de eventos adversos, naturais ou provocados pelo homem sobre um ecossistema vulnerável, causando danos humanos, materiais ou ambientais com prejuízos econômicos e sociais.

De outro lado, há um movimento intenso, inclusive na América Latina e no Brasil, na direção de melhor compreender os mecanismos que levam aos desastres. Wilches-Chaux (1993), Ribeiro (1995) e Valêncio (2009) mostram que o desastre é relacionado a fenômenos naturais, mas substancialmente é um fenômeno social. Nessa perspectiva sociológica, tais fenômenos são tratados como evitáveis e não naturais.

Maskrey (1993) e Wilches-Chaux (1993) tratam desse tema sob a ótica da desnaturalização dos desastres. Chamam a atenção para o fato de que a definição do desastre usualmente é feita a partir dos efeitos do evento, e não de suas causas. Redefinir o desastre significa, portanto, analisar a convergência de fenômenos que leva a sua ocorrência. Há um sistema formado por conjuntos com elementos em contínua interação, que envolve dinâmicas de estruturas e de processos. Durante os desastres, tais sistemas buscam a mudança: transformam-se com o intuito de sobreviver e conservar a identidade. Sinteticamente, os desastres teriam um caráter sistêmico.

Em outra definição, Ribeiro (1995) defende que independentemente da causa imediata atribuída a um desastre, esses consistem em processos de ruptura social, onde estão presentes processos causais sistêmicos e estruturais. Definições como de desastre natural ou de desastre tecnológico remetem a uma ótica exclusiva de causalidade genética, e são pouco vantajosos para a compreensão desses fenômenos.

Valêncio (2009) também argumenta nessa direção, ao colocar os desastres como objetos da sociologia, ou seja, como passíveis de investigação que vai além das variáveis intrínsecas ao fenômeno natural que os gera. Nessa disciplina, os desastres são compreendidos através das interpretações sobre a estrutura e dinâmica social, de modo multidimensional e multiescalar, com destaque ao papel do Estado e suas instituições, que, assim como o território físico, o ambiente e as populações, também possui graus de vulnerabilidade para lidar com os fenômenos denominados desastres.

Nesse sentido, certamente há importância de análises que compreendam os múltiplos aspectos que estão na gênese do risco e dos desastres: geomorfologia, economia, política e demografia, entre outros.

No Brasil, o tema da urbanização é central para o entendimento dos desastres. Essa perspectiva tem emergido recentemente, e foi sistematizada por Carmo (2014). Sua reflexão é de que o país representa emblematicamente a geração desigual dos ganhos e custos sociais e ambientais advindos do binômio industrialização/desenvolvimento econômico, e que tanto os desastres como a urbanização revelam tais desigualdades. A concepção do "desastre como um processo socialmente construído" 
teria como gênese a cidade desigual, expressa entre as diversas formas de assentamentos urbanos, principalmente entre aqueles precários, conhecidos como aglomerações subnormais, favelas, entre outros, e assentamentos diversos (grupo heterogêneo, que inclui áreas e domicílios não precários das mais amplas camadas sociais). Nessa cidade, a ocupação de áreas consideradas ambientalmente de risco ocorre pela mediação do mercado imobiliário no acesso à habitação, ou seja, é a concretização da distribuição desigual do desenvolvimento no plano do espaço urbano.

Dentro desse escopo, a compreensão dos desastres pela ótica dos estudos de população pode se valer de uma longa tradição de pesquisas que permite compreender o processo de urbanização e suas externalidades negativas, principalmente em termos dos riscos ambientais e sociais. Para tal, destacamos a necessidade de dialogar com duas áreas de pesquisa em plena expansão.

A primeira está nas perspectivas dos estudos sobre risco (MARQUES, 2010; 2011; 2012; MARANDOLA JR., MARQUES, PAULA e CASSANELI, 2013), vulnerabilidade (HOGAN e MARANDOLA JR., 2012; OJIMA e MARANDOLA JR., 2010) e resiliência (MARQUES, 2014), conceitos que trazem diferentes perspectivas da relação sociedade e ambiente (MARANDOLA JR., 2008).

A segunda área são os estudos de adaptação às mudanças ambientais. Tal interface é necessária, pois a discussão sobre os impactos sociais das mudanças ambientais tem como um de seus elementos centrais o debate sobre o crescimento dos desastres e a necessidade de construir respostas que minimizem os danos (IPCC, 2012).

Em síntese, uma definição de desastre que nos parece profícua é de que sua ocorrência está relacionada a eventos-perigo que trazem impactos extremos a situações de vulnerabilidade social e ambiental, afetando e/ou comprometendo a reprodução social dos impactados (LAVEL et al., 2012). Sua ocorrência não depende, necessariamente, de um perigo extremo, mas sim das condições de vulnerabilidade. Tal definição é usual nos eventos de deslizamentos e inundações. Nesse artigo, nossa proposta é também considerar como um desastre os fenômenos de seca e estiagem no Sudeste brasileiro. Nesse sentido, ressaltamos que é preciso levar a sério as seguintes dimensões desse processo:

1. A seca prolongada é consequência de um conjunto de fatores, tanto climáticos como sociais e institucionais. Porém, só é possível falar em desastre em função da incapacidade da sociedade em lidar com esse evento.

2. Tanto do ponto de vista intersetorial como intraurbano, os impactos e a recuperação do desastre serão sentidas de modo desigual. Diferentes setores de atividade e populações diversas não são afetados da mesma maneira nem possuem as mesmas condições de lidar com os desastres.

3. A seca, como desastre, necessariamente leva a um processo de ruptura (Ribeiro, 1995). Embora lenta, essa ruptura pode ser vislumbrada na reconfiguração dos aspectos estruturais da questão hídrica, tanto nas dimensões de demanda como de oferta.

Ao contrário dos eventos de deslizamento e inundações, que são pontuais e permitem estimações de impactos e respostas de modo mais rápido, a extensão da seca no Sudeste ainda é desconhecida e dificulta uma compreensão mais acurada dos seus impactos. Ainda assim, a urgência da crise já permite o desenho de alguns de seus elementos principais. Ao longo das próximas sessões, exploraremos essas questões, enfatizando as dinâmicas no Estado do Rio de Janeiro.

\section{DINÂMICAS FLUMINENSES}

Como os desastres ocorrem a partir de uma convergência de fenômenos relacionados à interação sociedade e ambiente, o entendimento de seus impactos e respostas demanda o desenho do quadro mais amplo do desenvolvimento social e econômico da região em questão.

O Estado do Rio de Janeiro passou por importantes transformações a partir da década de 1980 em relação ao seu tecido urbano e à distribuição espacial da população. Fruto da dependência dos investimentos federais no período pré-1980, esse passou por uma semi-estagnação econômica nessa década, a despeito da grande quantidade de investimentos públicos já feitos para a dinamização das 
suas diversas regiões. Com a retomada dos investimentos, a partir da década de 2000 , diversos indicadores, inclusive demográficos, apresentaram melhora (JUNIOR, 2013).

Nesse período, houve inserção de mudanças na orientação espacial dos investimentos e da atividade produtiva, com ascensão da indústria de diversos setores permitindo que, além da Região Metropolitana do Rio de Janeiro, as regiões do Médio Paraíba, o Norte Fluminense, as Baixadas Litorâneas e a Costa Verde apresentassem maior dinamismo econômico (JUNIOR, 2013). A divisão do Rio de Janeiro segundo as regiões de Governo está colocada na Figura 1.

Atualmente, a Região Metropolitana do Rio de Janeiro continua sendo a que mais concentra população (74,2\% do total estadual em 2010), com crescimento expressivo dos municípios de seu entorno. Nas demais regiões, o Médio-Paraíba se destaca pelos investimentos no setor secundário, principalmente nas indústrias automobilística e siderúrgica; o Norte, em função das atividades petrolíferas na Bacia de Campos, e o potencial turístico nas regiões litorâneas, ao Sul (Costa Verde) e Norte (Baixadas Litorâneas), juntamente com a Região Serrana (onde também há destaque para a agricultura). Já o Noroeste, tradicionalmente agrícola, tem apresentado maior estagnação (ERVATTI, 2003; JUNIOR, 2013; SILVA, 2011).

Nesse quadro geral, o aumento dos investimentos ao longo da última década dinamizou a economia estadual, com melhoria nos indicadores da atividade econômica, assim como promoveu sua interiorização e diversificação industrial. Houve queda das taxas de desocupação, aumento da formalização dos vínculos e, em medidas diferentes para cada uma das regiões, aumento dos salários pagos (JUNIOR, 2013).

Fig. 1: Regiões de Governo do Estado do Rio de Janeiro.

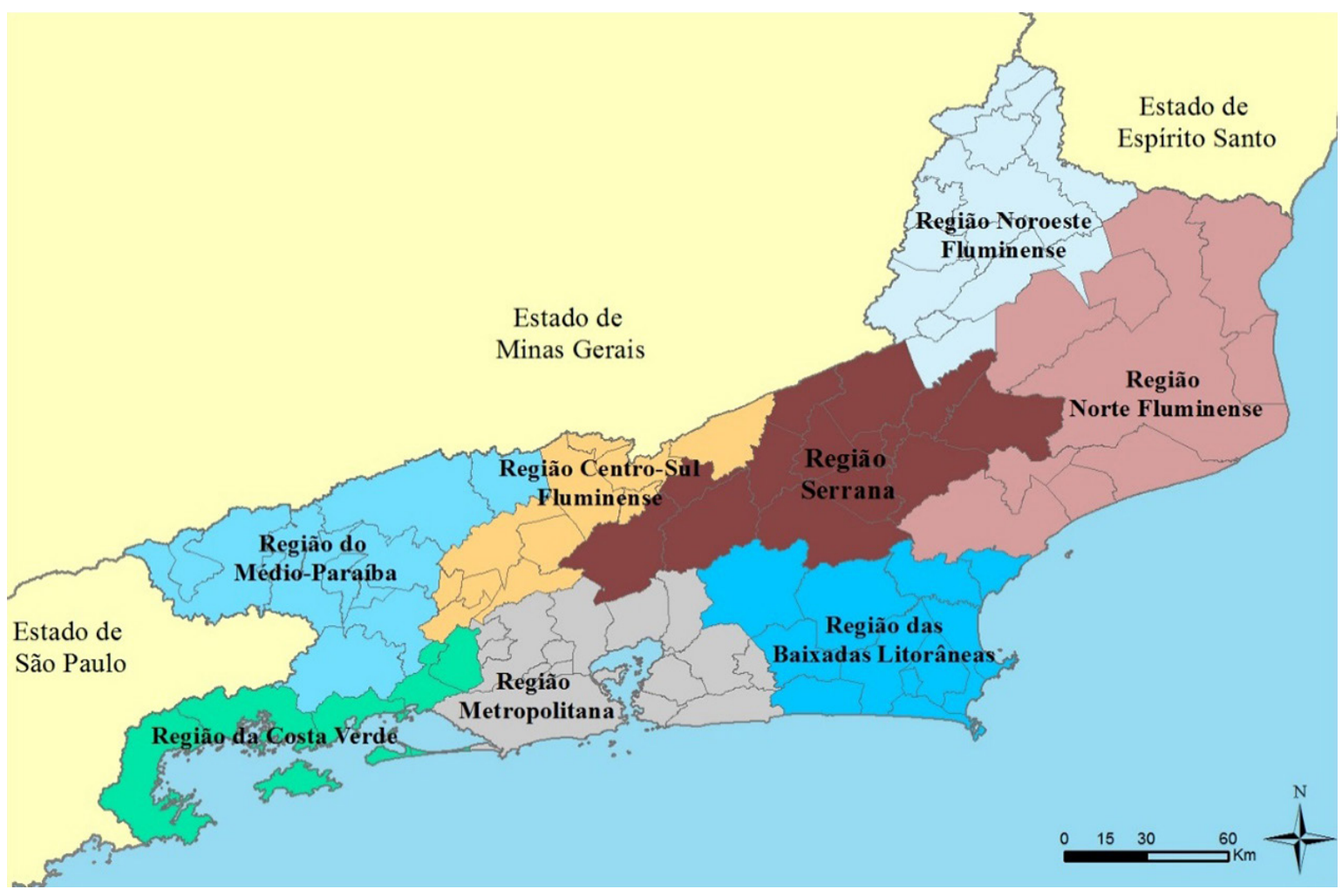

Fonte: IBGE, Malhas digitais do Censo Demográfico 2010.

No plano demográfico houve uma retomada do crescimento populacional na década de 2000 em relação à década anterior, principalmente em função da migração. Em termos gerais, a população urbana do Estado já era de $96,71 \%$ em 2010, sendo que 78,26\% dos municípios possuíam mais de $75 \%$ da população como urbana.

Em termos habitacionais, a Fundação João Pinheiro estimou o déficit habitacional no Rio de Janeiro em 2000 em 505.211 unidades (FJP, 2005) e em 2010 em 515.617 unidades (FJP, 2013). Usando outra metodo- 
logia, a Caixa Econômica Federal calcula a demanda habitacional em 656.737 unidades para 2009, o que representa 12,19\% do total de unidades (CEF, 2014). Já se considerarmos apenas os domicílios nos aglomerados subnormais (geralmente denominados "favelas"), e os consideramos como inadequados, esses eram 582.163, representando 11,10\% do total (segundo o Censo Demográfico 2010). Alguns dos municípios com as situações mais precárias foram Petrópolis e Niterói. Esses possuíam, respectivamente, 6.236 e 18.592 moradias em aglomerados subnormais em aclive/declive acentuado (mais propensos a deslizamentos). Em percentuais, isso representa 85,8\% e 76,58\% do total de domicílios em aglomerados subnormais.

Embora não possamos falar de um aumento ou redução do número absoluto do déficit habitacional devido às diferenças metodológicas das pesquisas, pode-se notar que a situação habitacional permanece sem resolução adequada, ou seja, não demonstra, aparentemente, a mesma melhora vislumbrada dos indicadores econômicos.

De modo mais detalhado, a Tabela 1 traz os dados do Censo Demográfico 2010 para os municípios do Rio de Janeiro que possuem aglomerados subnormais, indicando como a precariedade de estrutura urbana continua sendo um traço importante de cidades em diversas regiões do Estado.

Tabela 1: Domicílios particulares permanentes em aglomerados subnormais no Rio de Janeiro, por topografia predominante, 2010.

\begin{tabular}{|c|c|c|c|c|c|c|c|c|c|}
\hline \multirow{3}{*}{ Município } & \multirow{2}{*}{\multicolumn{3}{|c|}{ Total de domicílios }} & \multicolumn{6}{|c|}{$\begin{array}{l}\text { Domicílios em aglomerados subnormais por } \\
\text { topografia predominante }\end{array}$} \\
\hline & & & & \multicolumn{2}{|c|}{ Plano } & \multicolumn{2}{|c|}{$\begin{array}{l}\text { Aclive/declive } \\
\text { moderado }\end{array}$} & \multicolumn{2}{|c|}{$\begin{array}{l}\text { Aclive/declive } \\
\text { acentuado }\end{array}$} \\
\hline & Total & $\begin{array}{l}\text { Em aglomerados } \\
\text { subnormais }\end{array}$ & $\begin{array}{l}\% \text { em aglomerados } \\
\text { subnormais }\end{array}$ & Abs. & $(\%)$ & Abs. & $(\%)$ & Abs. & $(\%)$ \\
\hline Araruama & 35.807 & 6.086 & 17,00 & 5.309 & 87,23 & 634 & 10,42 & 143 & 2,35 \\
\hline Belford Roxo & 145.677 & 10.397 & 7,14 & 2.276 & 21,89 & 566 & 5,44 & 7555 & 72,67 \\
\hline Cabo Frio & 59.443 & 12.287 & 20,67 & 10.534 & 85,73 & 1182 & 9,62 & 571 & 4,65 \\
\hline Campos dos Goytacazes & 142.416 & 4.588 & 3,22 & 4.588 & 100,00 & 0 & 0,00 & 0 & 0,00 \\
\hline Magé & 70.394 & 5.584 & 7,93 & 4.614 & 82,63 & 896 & 16,05 & 74 & 1,33 \\
\hline Niterói & 169.237 & 24.278 & 14,35 & 1.249 & 5,14 & 4437 & 18,28 & 18592 & 76,58 \\
\hline Petrópolis & 96.319 & 7.268 & 7,55 & 211 & 2,90 & 821 & 11,30 & 6236 & 85,80 \\
\hline Rio de Janeiro & 2.144 .445 & 426.479 & 19,89 & 243.475 & 57,09 & 118372 & 27,76 & 64632 & 15,15 \\
\hline São João de Meriti & 147.450 & 14.453 & 9,80 & 7.206 & 49,86 & 1288 & 8,91 & 5959 & 41,23 \\
\hline Teresópolis & 53.782 & 12.586 & 23,40 & 2.391 & 19,00 & 1504 & 11,95 & 8691 & 69,05 \\
\hline Volta Redonda & 84.307 & 10.142 & 12,03 & 2.974 & 29,32 & 2075 & 20,46 & 5093 & 50,22 \\
\hline Total Estado RJ & 5.243 .011 & 582.163 & 11,10 & 316.427 & 54,35 & 138.520 & 23,79 & 127.216 & 21,85 \\
\hline
\end{tabular}

Fonte: IBGE, Censo Demográfico 2010.

\section{RETRATOS DE DESASTRES RECENTES NO RIO DE JANEIRO}

Embora longe de ser resolvida, a questão da falta de água já é um tema bastante debatido no contexto paulista, ao menos desde o verão de 2013/2014, que teve baixos índices pluviométricos. Além disso, já há análises que incorporam a dualidade no problema, com a água exercendo tanto uma pressão em casos de excesso como também no caso da sua falta (CARMo et al.; 2014a; 2014b).

Para o caso do Rio de Janeiro, já há uma bibliografia que trata dos seus diversos desastres nesse início do século (DOURADO et al., 2012; CASTILHO et al, 2012; FREITAS et al., 2012; LICCO, 2013; YOUNG et al., 2014), mas ainda é incipiente a discussão sobre a estiagem enquanto um desastre. 
Apesar de incompletas, existem atualmente fontes de dados que retratam os desastres para o Brasil como um todo, no nível do município.

A Munic é uma pesquisa de informações básicas municipais feita pelo IBGE, que coleta junto aos municípios informações sobre as instituições públicas municipais e geralmente é feita anualmente. $\mathrm{O}$ questionário básico da última edição publicada (2013) investigou informações presentes nas versões anteriores (perfil dos gestores municipais, recursos humanos, legislação e instrumentos de planejamento, saúde, meio ambiente e gestão da política de gênero) e pela primeira vez trouxe dados sobre a gestão de riscos e resposta a desastres. Foram focados somente os riscos em áreas urbanas relacionados a deslizamentos, enchentes e inundações. Contudo, seu método de pesquisa gera resultados que podem ser questionados. Como a prefeitura é o informante principal, as respostas são obtidas através de consulta a profissionais que supostamente detém as informações corretas em relação a cada uma das áreas pesquisadas (IBGE, 2013). Dada a grande diversidade de capital humano e técnico presente nas prefeituras, e também a falta de dados precisos sobre os riscos ambientais, os dados da Munic sobre desastres são, por vezes, não confiáveis.

Para analisar os dados, consideramos os três tipos de riscos presentes no questionário da Munic 2013: enchentes ou inundações graduais, enxurradas ou inundações bruscas e escorregamentos ou deslizamentos. Somados, a Munic contabilizou 4.969 eventos de deslizamentos, 191 inundações bruscas e 647 inundações graduais entre 2008 e 2103. Vale lembrar que não perguntou sobre o número de desastres, mas sim sobre o número de eventos. A distribuição espacial dos municípios atingidos por inundações e deslizamentos de acordo com a Munic está posta nas figuras 1, 2 e 3.

Figura 1: Ocorrência de deslizamentos e escorregamentos de encostas nos últimos 5 anos (20092013), por município.

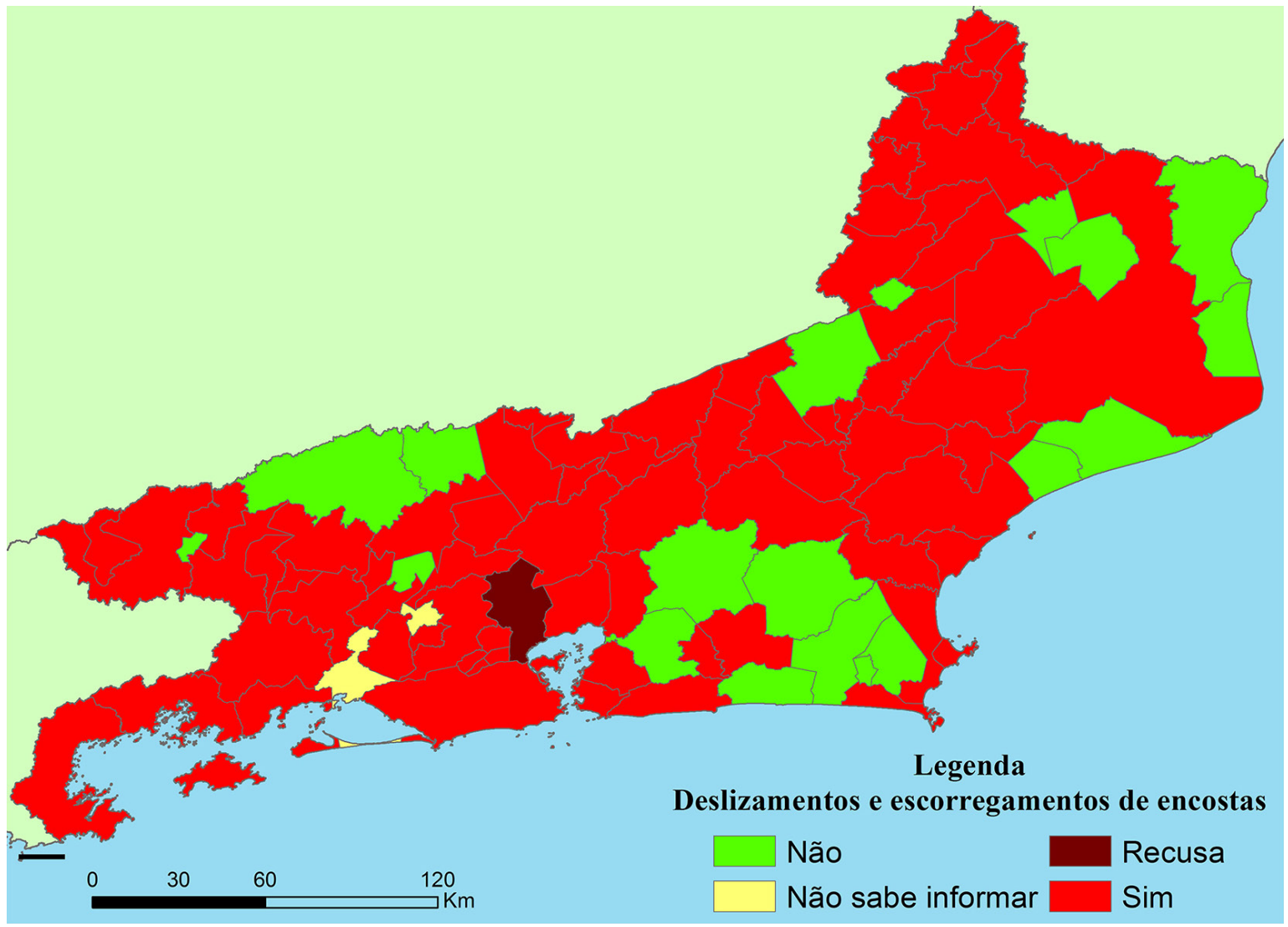

Fonte: IBGE - Malha Digital dos Municípios 2010. MUNIC 2013. 
Figura 2: Ocorrência de enxurradas e inundações bruscas nos últimos 5 anos (2009-2013), por município.

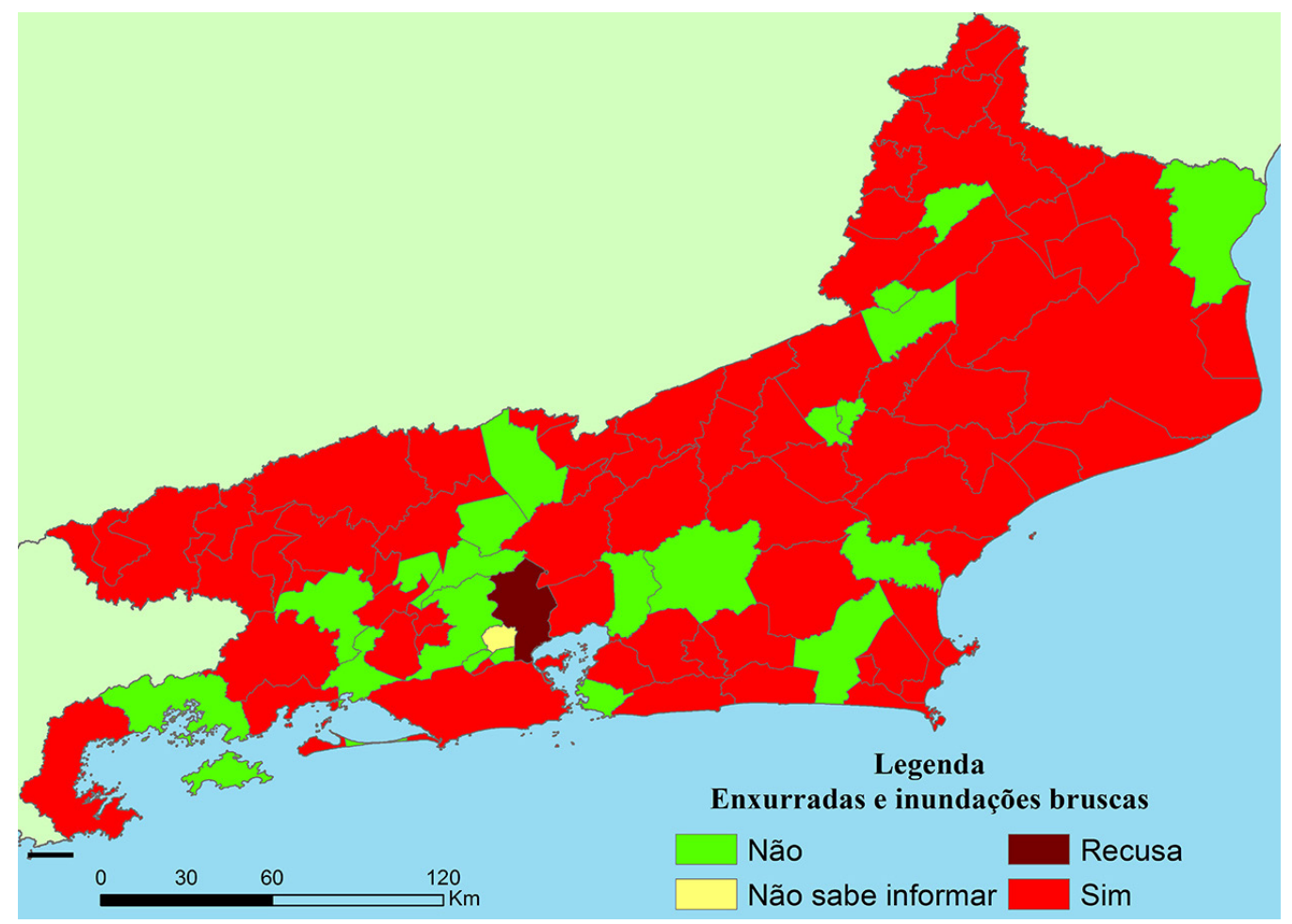

Fonte: IBGE - Malha Digital dos Municípios 2010. MUNIC 2013.

Figura 3: Ocorrência de enxurradas e inundações bruscas nos últimos 5 anos (2009-2013), por município.

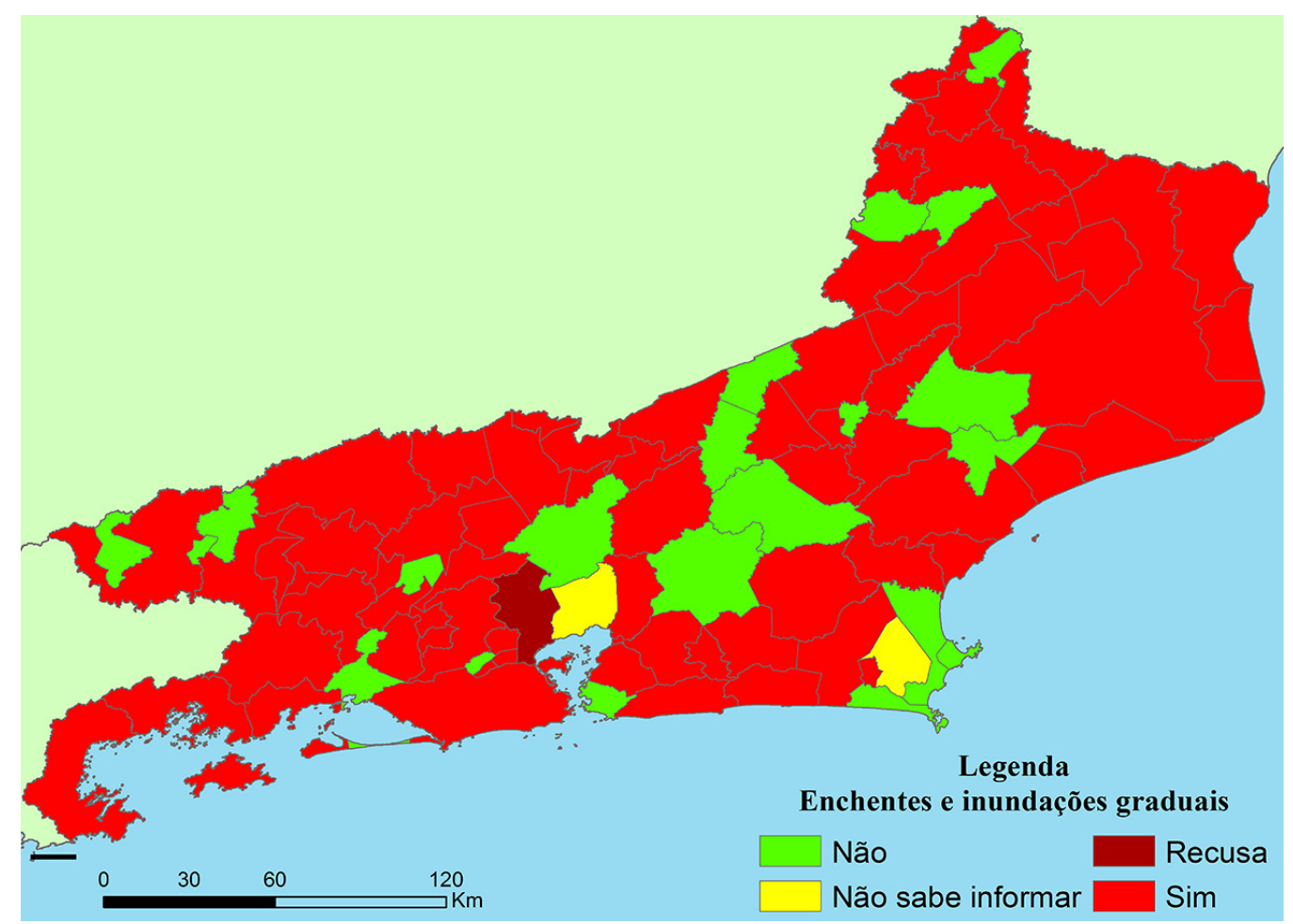

Fonte: IBGE - Malha Digital dos Municípios 2010. MUNIC 2013. 
Ao todo, entre 2009 e 2013, 70 municípios declararam passar por deslizamentos, 69 por enxurradas e inundações bruscas, e 68 foram atingidos por enchentes e inundações graduais. A quase totalidade dos municípios declarou passar por algum tipo de evento. Os deslizamentos ocorreram inclusive nos municípios costeiros, que possuem também áreas de elevado declive, e não somente planícies. De outro lado, municípios intensamente afetados por eventos pluviométricos intensos, como Petrópolis e Nova Friburgo, declararam não ter sido afetados por enchentes e inundações graduais, mas somente para inundações bruscas. Niterói, que reconheceu situação de calamidade pública em virtude de enxurradas em 2010 (UFSC, 2013a), declarou não ter passado por nenhum tipo de evento de inundação. No mesmo ano também foram registradas inundações graduais e bruscas em Angra dos Reis (UFSC, 2013a), embora, segundo a Munic 2013, tenham ocorrido apenas inundações bruscas. Nesse sentido, os dados sobre a ocorrência de eventos devem ser observados com resguarda.

Contudo, uma série de outras informações estão presentes na Munic. Ela conta com quesitos sobre afetados (pessoas e edificações), estimativas da população vulnerável, planejamento e gerenciamento de risco, além de incluir os órgãos existentes. As figuras 4 e 5 trazem informações sobre o total de afetados e sobre o pessoal de Defesa Civil contratado em cada município.

Figura 4: Total de pessoas afetadas por riscos de inundações e deslizamentos em razão do tamanho da população (2013).

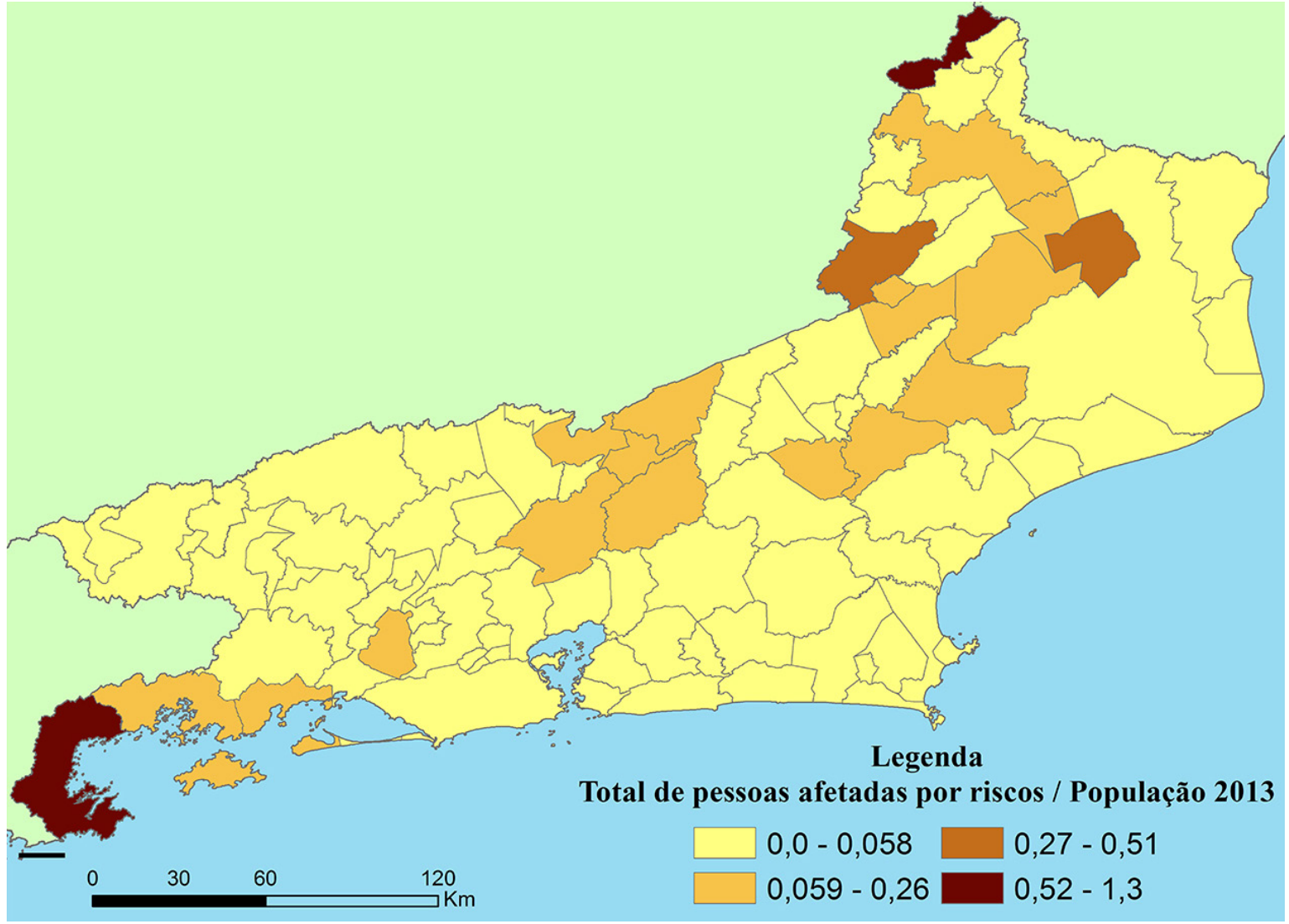

Fonte: IBGE - Malha Digital dos Municípios 2010. MUNIC 2013.

De maneira geral, os municípios que tiveram as maiores porcentagens de suas populações atingidas pelos riscos de inundações e deslizamentos estão no Sul, na chamada Costa Verde, e na Região Serrana. Há um "corredor" de municípios nessa área, formado por Petrópolis, passando por Teresópolis e chegando a Cardoso Moreira, já no Norte do Estado, onde a Serra é cortada por áreas de planícies. 
Figura 5: Total de pessoal empregado na Coordenação Municipal de Defesa Civil.

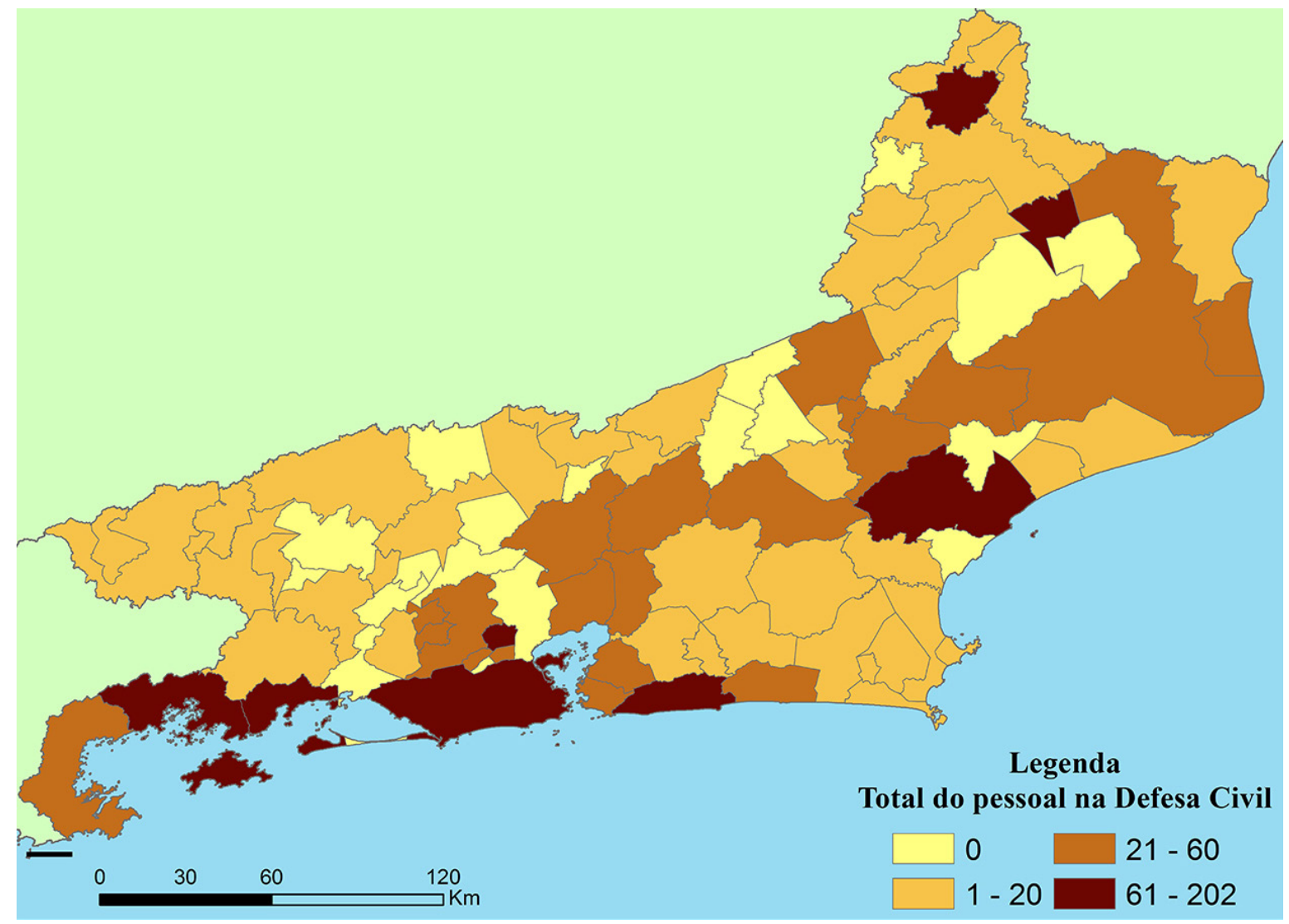

Fonte: IBGE - Malha Digital dos Municípios 2010. MUNIC 2013.

Dos 92 municípios do Estado, 80 contam com Defesa Civil. No entanto, a distribuição do total de funcionários é distinta entre os municípios. Os com maior quantidade de recursos humanos são a capital, municípios do Litoral Sul, da Região Serrana e da Região Norte. Por um lado, os eventos extremos passados pelas diversas regiões do Estado durante os últimos anos parecem ter surtido efeito na ampliação das Defesas Civis. Por outro, ainda é notável que, entre os municípios, a mediana de funcionários na instituição seja igual a 6, com um desvio-padrão de 31,74. Há grande diversidade no tamanho das Defesas Civis, com metade delas empregando 6 funcionários ou menos.

Uma base mais confiável para os dados sobre desastres, mas com menor acesso público aos dados e ausência de informações institucionais, é o Atlas brasileiro de Desastres naturais, feito a partir de uma parceria entre a Secretaria Nacional de Defesa Civil e o Centro Universitário de Estudos e Pesquisas sobre Desastres (Ceped/UFSC). A base conta com dados dos registros oficiais dos desastres ocorridos entre 1990 e 2012, a partir de uma série de instrumentos: Notificação preliminar de desastres (Nopred), Avaliação de Danos (Avadan) e decretos municipais e estaduais de situação de emergência ou calamidade pública. Mais recentemente (a partir de 2012), o Nopred e o Avadan foram substituídos pelo Formulário de Informações sobre Desastres (Fide). Além de ter uma cobertura mais confiável, tal base também contabiliza uma tipologia maior de desastres, com as categorias movimentos de massa, erosão, inundações, enxurradas, alagamentos, ciclones, tempestade local, estiagem/seca, onda de frio e incêndio florestal. Contudo, vale ressaltar que a base também tem limitações, dada a falta de padronização dos documentos oficiais, ausência de metodologia para coleta e armazenamento dos dados, falta de integridade histórica e falhas no preenchimento dos documentos sobre desastres (UFSC, 2013b).

Vale ressaltar que, nesse caso, registrou-se o desastre, e não os eventos que o geraram. Essa é uma diferença fundamental em relação a Munic, a despeito de todas as diferenças metodológicas entre elas.

No Atlas, os registros de estiagem e seca totalizaram 12 eventos, todos localizados no Norte do Estado, nas regiões Norte e Noroeste Fluminense. Já as enxurradas (inundações bruscas) totalizaram 
251 registros, distribuídos em todas as regiões do Estado e 86\% de seus municípios. As inundações (ou enchentes) foram registradas 190 vezes. Embora estejam presentes em todas as regiões, a mais afetada foi o Norte-Noroeste Fluminense. Para alagamentos, houve 56 registros, concentrados na Região Metropolitana do Rio de Janeiro. Os movimentos de massa foram concentrados na região Sul e na mesorregião metropolitana, com os eventos mais intensos em Petrópolis, Niterói e Angra dos Reis. Ao todo, foram 153 registros. Somadas, essas 4 classificações correspondem a 650 registros, o que equivale a $89,4 \%$ do desastres registrados no período. A mesorregião metropolitana (que inclui a Região Serrana) foi a mais afetada, seguida pela região Noroeste.

Dos diversos eventos relacionados a altas e baixas pluviometrias que atingiram o Rio de Janeiro durante a última década, os casos dos deslizamentos no "Morro do Bumba", em Niterói, e na Região Serrana, e a seca que se configura mais fortemente no início de 2015, principalmente na Região Metropolitana do Rio de Janeiro, são emblemáticos das configurações de situações de eventos extremos no estado.

Em Niterói, o que ficou conhecido como "desastre do Morro do Bumba", no bairro Viçoso Jardim, representa uma dinâmica típica no processo de urbanização brasileiro. A área em que o desastre ocorreu não atraia interesse do mercado imobiliário e foi pouco priorizada no seu potencial para uso urbano. Sem acesso à terra urbana, populações com menor poder aquisitivo ocuparam a região e seu entorno a partir da década de 1960, sendo que entre 1970 e 1986 o lugar funcionou para alojamento de lixo. Após sua desativação como vazadouro de lixo, foram iniciadas as primeiras ocupações na região do desastre, com moradias de alvenaria irregulares em um local com elevado declive. Durante as décadas posteriores o local teve sua ocupação consolidada, com cerca de 300 residências construídas acima do depósito de lixo. Era a configuração de um desastre anunciado. Em abril de 2010, chuvas de aproximadamente $323 \mathrm{~mm}$ em 24 horas desencadearam no deslizamento de terra e na explosão de gás proveniente do lixo aterrado. As estimativas apontam que entre 50 e 166 pessoas morreram, e 200 domicílios foram destruídos (LOGUERCIO e ZAMBONI, 2012, LOGUERCIO, 2013; SILVA, 2012; DOURADO et al., 2012).

Já a Região Serrana do RJ é, ambientalmente, uma área altamente propícia a deslizamentos: possui uma geografia de montanhas, uma rica hidrografia, subsolo de rocha coberto com pequena camada de terra, elevado desmatamento e implantação de florestas exóticas para fins industriais. Assim, as chuvas superiores a 400 milímetros em 24 horas durante entre os dias 11 e 12 de janeiro de 2011 levaram a enchentes e deslizamentos em diversos pontos da região, atingindo infraestruturas públicas, residências, populações de alto e baixo poder aquisitivo, comprometendo serviços básicos e a economia regional (FREITAS et al., 2012). Na região, os próprios equipamentos públicos foram instalados em locais considerados de risco (BRASIL, 2011). Ao todo, estima-se que 22.604 pessoas tenham ficado desalojadas, 8.795 desabrigadas e 918 tenham sofrido óbito. Os municípios mais afetados foram Petrópolis, Nova Friburgo e Teresópolis (freitas et al., 2012).

O caso da Região Serrana evidenciou a dimensão crônica dos riscos ambientais, já que é reflexo de uma gestão ambiental, principalmente dos riscos, dissociada do planejamento urbano como um todo. Desse modo, tanto a quantidade de chuvas como a dinâmica local, com construções inadequadas, áreas de proteção ambiental ocupadas, falta de estrutura de drenagem e desmatamento generalizado convergiram para a ocorrência do que foi conhecido como um desastre (CASTILHO, OLIVEIRA, FABRIANI, 2012).

A magnitude do evento foi tal que a Câmara de Deputados Federal montou uma comissão externa para avaliar o desastre, o que resultou em uma sistematização grande de informações sobre o mesmo (CAMARA DOS DEPUTADOS, 2013).

Em ambos os casos, notamos que situações parecidas já se repetiam anteriormente. A existência de alta pluviometria, com consequentes deslizamentos que geravam perdas humanas, eram relativamente comuns nas regiões. Não foram dinâmicas de exceção, ao contrário, foram desastres precedidos por uma série de eventos similares, em menor escala (LOGUERCIO, 2013; FREITAS et al., 2012).

Demograficamente, esses desastres são os mais evidentes em termos de mortalidade, como denotamos através dos dados do Sistema de Informações sobre Mortalidade (sım, Ministério da Saúde) categorizados na Tabela 2. 
Tabela 2: Mortalidade por desastres (causas agrupadas na categoria exposição às forças da Natureza, grupos $\mathrm{X}_{30} \mathrm{-} \mathrm{X}_{39}$ ) no Rio de Janeiro (2010-2012).

\begin{tabular}{|c|c|c|c|c|}
\hline Município & Ano & & & \\
\hline & 2010 & 2011 & 2012 & Total \\
\hline Angra dos Reis & 25 & - & - & 25 \\
\hline Niterói & 164 & - & - & 164 \\
\hline Nova Friburgo & - & 349 & - & 349 \\
\hline Petrópolis & 2 & 45 & - & 47 \\
\hline Rio Claro & 7 & - & - & 7 \\
\hline Rio de Janeiro & 45 & 23 & 2 & 70 \\
\hline São Gonçalo & 13 & 1 & - & 14 \\
\hline São João de Meriti & 1 & - & - & 1 \\
\hline São José do Vale do Rio Preto & - & 2 & - & 2 \\
\hline Sapucaia & - & - & 16 & 16 \\
\hline Sumidouro & - & 17 & - & 17 \\
\hline Teresópolis & - & 272 & 4 & 276 \\
\hline
\end{tabular}

Fonte: SIM/DATASUS.

Contudo, ainda é grande a dificuldade em lidar com as bases de dados que contenham variáveis demográficas (principalmente migração e mortalidade) para a compreensão de dinâmicas populacionais decorrentes de desastres. O trabalho de Carmo e Anazawa (2014) tem esse objetivo para o caso da mortalidade. Analisando os dados do EM-DAT, do Atlas Brasileiro de Desastres Naturais e do SIM, os autores fazem uma análise descritiva das informações sistematizadas e as comparam. A comparação mostrou que, com as bases de dados atuais, não é possível afirmar se os desastres e a mortalidade por desastres estão aumentando no país, por conta das variações dos eventos que ocorrem a cada ano. O levantamento das informações mostrou a importância do desastre ocorrido na Região Serrana do Rio de Janeiro em 2011, em especial no município de Nova Friburgo. Neste município, os diversos grupos etários de ambos os sexos foram afetados: o grupo de 5 a 9 anos foi o mais atingido entre homens e mulheres, além dos de 20 a 24 anos (para mulheres) e 30 a 34 (para homens) (CARMo e ANAZAWA, 2014).

Não só pelo excesso, mas pela falta de água, os desastres são presentes na dinâmica de toda a região Sudeste na presente década. Como vimos, contudo, há pouco reconhecimento dessa situação como um desastre, ou seja, como a configuração de um processo de vulnerabilidade institucional e social frente à dinâmicas ambientais, que podem levar a rupturas nessas dinâmicas.

No Rio de Janeiro, o abastecimento de água é garantido pela bacia do Rio Paraíba do Sul, que possui uma área de drenagem com cerca de $55.500 \mathrm{~km}^{2}$, com nascentes no estado de São Paulo e percurso pelos Estados de Minas Gerais e Rio de Janeiro.

Nessa bacia estão localizados os principais reservatórios para o abastecimento do estado, principalmente por cobrirem a Região Metropolitana: Jaguari, Paraibuna, Santa Branca e Funil. Vale destacar que esse é um sistema complexo, com dois subsistemas (Paraíba e Lajes), onde há transposição do Rio Paraíba do Sul para o Rio Guandu, visando garantir a maior parte do abastecimento da RMRJ (ANA, 2015).

Os dados da Agência Nacional de Águas mostram que houve, em 2014, uma drástica redução no volume do reservatório equivalente (relativo ao volume útil total do sistema). Conforme a Figura 6, ao contrário do que ocorreu ao longo das décadas de 1990 e 2000, no verão de 2013/2014 não aconteceu um aumento significativo da disponibilidade do sistema no período chuvoso. Houve uma redução drástica do seu volume, que caiu de aproximadamente 50\% para quase o\%. Entre novembro de 2014 e o início de março de 2015, houve alguma recuperação propiciada pelas chuvas. Mesmo assim, o reservatório equivalente ainda não alcançava os 10\% de seu volume útil no início de março (Tabela 3). 
Figura 6: Reservatório equivalente - Volume acumulado (\% de Volume útil, 1993-2014).

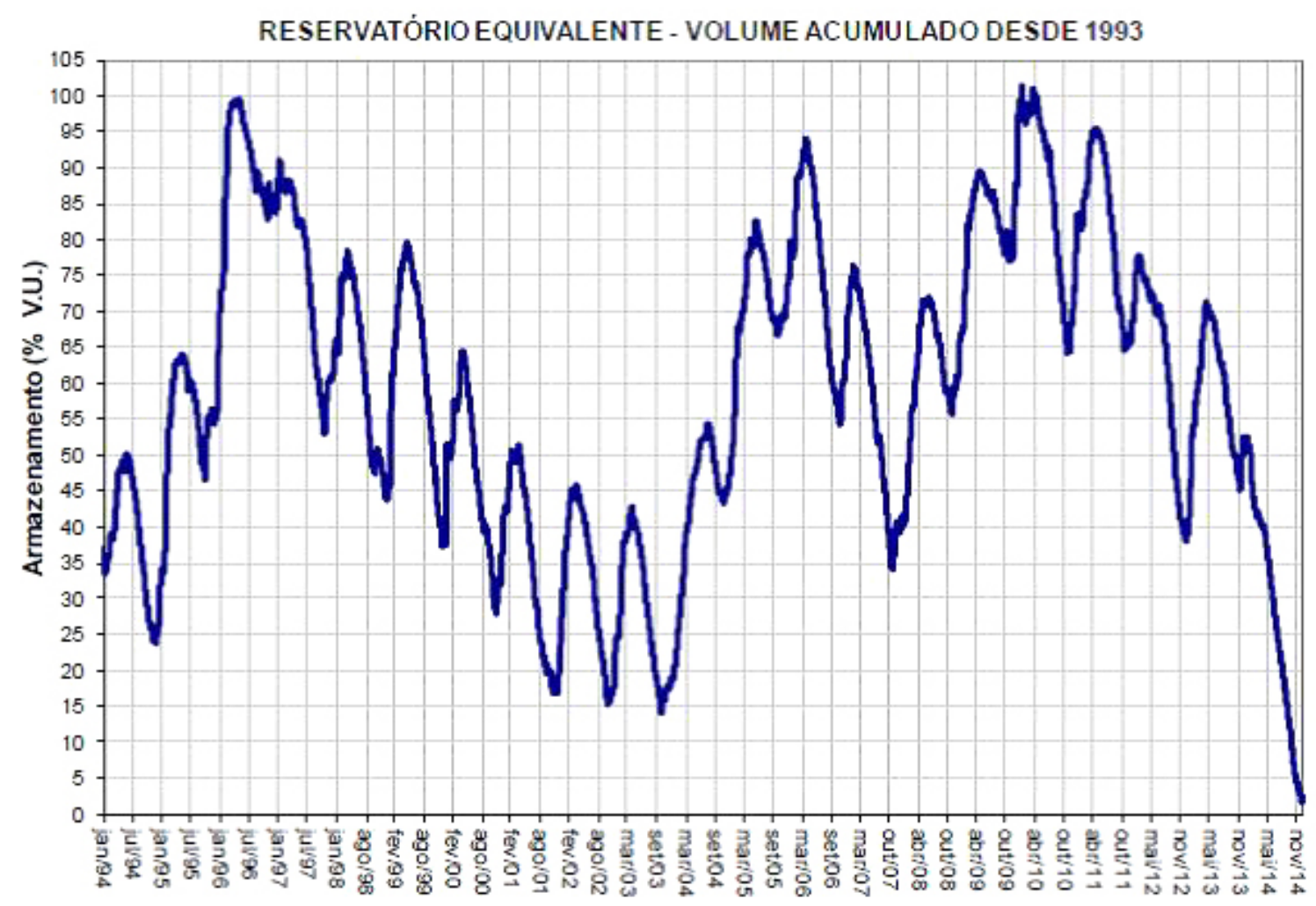

Fonte: ANA, 2015

Tabela 3: Situação dos reservatórios do Sistema Paraíba do Sul em o4/o3/2015.

\begin{tabular}{|c|c|c|c|c|}
\hline Reservatório & Cota $(\mathrm{m})$ & Vol. acum. $\left(\mathrm{hm}^{3}\right)$ & Vol. útil acum. & \% Vol. útil \\
\hline Paraibuna & 695,15 & 2.151 & 55 & 2,09 \\
\hline Santa Brava & 605,36 & 136 & 4 & 1,46 \\
\hline Jaguari & 605,97 & 522 & 79 & 9,96 \\
\hline Funil & 453,85 & 483 & 201 & 33,16 \\
\hline Reservatório equivalente & 3.292 & 339 & 7,81 & \\
\hline
\end{tabular}

Fonte: Boletim diário da Bacia do Rio Paraíba do Sul. ANA, 2015.

Por outro lado, a escassez de água é representada pela estiagem e seca. A estiagem pode ser considerada como o desastre de maior ocorrência e impacto, devido ao longo período de ocorrência, bem como a extensão das áreas atingidas. Caso a estiagem seja prolongada, configura-se em situação de seca, marcada pela interrupção do sistema hidrológico, ocasionando impactos severos sobre os sistemas ecológico, social, econômico e cultural. Sendo assim, as secas e estiagens, enquanto desastres, não devem ser caracterizadas apenas por índices pluviométricos abaixo do normal. Outros condicionantes devem ser considerados, como o manejo inadequado das bacias hidrográficas, intensificado pelo processo de ocupação destes locais (CASTRO, 2003).

É nesse quadro que se desenha o desastre da falta de água no Rio de Janeiro. Como um todo, avalia-se que toda a Região Metropolitana demanda ampliação do sistema, e que a grande maioria (81\%) dos municípios com abastecimento satisfatório é de municípios com população inferior a 50 mil habitantes (Tabela 4). 
Tabela 4: Diagnóstico do abastecimento de água no Rio de Janeiro, 2015.

\begin{tabular}{|l|c|c|c|}
\hline \multirow{2}{*}{\multicolumn{1}{c}{ Classes de cidades }} & Diagnóstico 2015 & & \\
\cline { 2 - 4 } & Abastecimento satisfatório & Requer investimentos & \\
\cline { 2 - 4 } & & Ampliação de sistema & Novo manancial \\
\hline Região Metropolitana & --- & 17 & --- \\
\hline População superior a 250 mil & 2 & 1 & --- \\
\hline População entre 50 mil e 250 mil & 7 & 7 & 2 \\
\hline População inferior a 50 mil & 38 & 15 & 1 \\
\hline Total & 47 & 40 & 3
\end{tabular}

Fonte: ANA, 2015

Assim, há um duplo movimento que merece forte atenção para a dinâmica de eventos extremos de baixa pluviometria no estado: há forte necessidade de ampliação do sistema nas áreas de maior concentração populacional, assim como há uma perspectiva de crise pela própria falta de água.

As questões de racionamento e rodízio também merecem atenção. Em 2008, ano da última edição da Pesquisa Nacional de Saneamento Básico - PNSB (IBGE, 2008), 38\% dos municípios fluminenses passavam por racionamento, em um ano em que o Sistema Paraíba do Sul teve entre 35\% e $75 \%$ de volume útil no reservatório equivalente. As causas do fenômeno foram diversas: em $35 \%$ dos casos havia insuficiência de água no manancial, para $28 \%$ deficiência na produção e em $26 \%$ deficiência na distribuição, em $26 \%$ dos casos se alegou que a população flutuante era a causa do racionamento, $42 \%$ atribuíram o problema à seca/estiagem e $14 \%$ também levantaram outros motivos. ${ }^{5}$ Dentre aqueles com racionamento, $45,7 \%$ tinham racionamento constante e $28,6 \%$ todos os anos, mas apenas na época da seca. Os demais $28,6 \%$ tinham racionamentos esporádicos.

\section{CONSIDERAÇÕES FINAIS}

Altas e baixas pluviometrias geraram, nesses 15 primeiros anos do século, uma série de eventos que foram classificados como desastres, mais pelo excesso do que pela ausência.

O Estado do Rio de Janeiro, que abriga a segunda maior metrópole do país, passou por três grandes eventos de deslizamentos que chamaram a atenção do país em um intervalo de dois anos, entre 2010 e 2011, em Angra dos Reis, na Região Serrrana e em Niterói. Classificar situações de deslizamentos e inundações como desastres passou a ser comum, embora muitas vezes enquanto desastres naturais, e não como desastres construídos a partir de dinâmicas sociais e institucionais.

Os dados das diversas fontes analisadas aqui indicam que tanto as situações de deslizamento e inundações, como as situações de falta da água foram parte da dinâmica sociedade e natureza nesse período. As pesquisas do IBGE (Munic e PNSB), o Atlas Brasileiro de Desastres Naturais, os dados do SIM, do CEMADEN e as informações da ANA são cruciais para uma melhor compreensão dos desastres em todo o território nacional. Contudo, tais fontes têm limitações, que podem e devem ser exploradas com o fim do aprimoramento da coleta dos dados. Por outro lado, a busca da compreensão sociológica do impacto desses eventos demanda o aprofundamento na análise dessas fontes, e também a melhor compreensão sobre as instituições que lidam com esses fenômenos. Os desastres relacionados à água (principalmente deslizamentos e inundações) ocorrem de maneira dispersa no território fluminense, ao mesmo tempo em que as instituições (como a Defesa Civil) que lidam com eles também estão presentes. Nesse caso, essa presença ainda não permitiu claros indícios sobre os aumentos da segurança.

Para a falta de água o desastre é construído lentamente, na medida em que a velocidade de queda nos reservatórios é maior do que a capacidade de planejamento do estado. Ou seja, o perigo (a concretude da falta de água) é iminente. Se considerarmos que esse fenômeno ocorre na sociedade de risco, segundo a construção do sociólogo alemão Ulrich Beck (BECK, 2011), a situação pode se agravar. Nessa sociedade, sobrepõem-se aos conflitos de distribuição da riqueza os conflitos de distribuição dos riscos. Porém, não há uma clara oposição de classe, já que os afetados não se opõem aos afetados.

5 A soma é superior a 100\% pois pode se apresentar mais de um motivo para o racionamento de água. 
Nesse caso, os não afetados seriam simplesmente os ainda não afetados.

A melhor compreensão dessa questão, assim como seu equacionamento, depende da melhoria da base de dados e de avanços em indicadores mais desagregados, como os relativos à frequência com que deslizamentos e inundações ocorrem, assim como à frequência do abastecimento de água na escala intraurbana.

\section{REFERÊNCIAS BIBLIOGRÁFICAS}

ANA. Região Metropolitana do Rio de Janeiro. 2010. Disponível em http://atlas.ana.gov.br/atlas/ forms/analise/RegiaoMetropolitana.aspx? $r m e=18$

ANA. Atlas Brasil: abastecimento urbano de água. 2015. Disponível em www.atlas.ana.gov.br.

BECK, U. Sociedade de risco: rumo a uma outra modernidade. São Paulo, Ed. 34, 2011.

BRASIL. Ministério do Meio Ambiente. Relatório de Inspeção Área atingida pela tragédia das chuvas Região Serrana do Rio de Janeiro. Brasília: Secretaria de Biodiversidade e Florestas; 2011.

CAIXA ECONÔMICA FEDERAL (CEF). Demanda habitacional no Brasil. Caixa Econômica Federal - Brasília: CAIXA, 2011. 170 p.

CÂMARA DOS DEPUTADOS. Comissão externa da Região Serrana do Rio de Janeiro, Brasília, 2013.

CARMO, R.L. Urbanização e Desastres: Desafios para a segurança humana no Brasil. In: CARMO, R.L.; VALENCIO, N. (orgs). Segurança humana no contexto dos Desastres. NEPo/UNICAMP, NEPED/UFSCAR, FMCJS, Campinas, 2014.

CARMO, R.L.; ANAZAWA, T.M.; JOHANSEN, I.C. Seca nas metrópoles: materialização de um desastre anunciado. Cadernos de trabalho da Rede Waterlat, v. 1, p. 92-110, 2014.

CARMO, R.L.; JOHANSEN, I.C.; ANAZAWA, T.M. Metrópoles bipolares: aspectos da dinâmica socioambiental e demográfica do excesso e da falta de água. In: XIX Encontro Nacional de Estudos Populacionais, 2014, São Pedro/sP. Anais do XIX Encontro Nacional de Estudos Populacionais, 2014. v. 1.

CARMO, R.L.; ANAZAWA, T.M. Mortalidade por desastres no Brasil: o que mostram os dados. Ciência e Saúde Coletiva, v. 19, p. 3669-3681, 2014.

CASTILHO, L.V.; Oliveira, P. M. de c.; Fabriani, C.B. Análise de uma tragédia ambiental e a participação da população no equacionamento dos problemas de moradia: um estudo de caso da tragédia na Região Serrana do Rio de Janeiro. In: Anais do VI Encontro Nacional da ANPPAS, 18 a 21 de setembro de 2012, Belém, 2012.

CASTRO, A.L.C. Manual de desastres: desastres naturais. Brasília, DF: Ministério da Integração Nacional, 2003.

CEMADEN. Relatório da Situação Atual e Previsão Hidrológica para o Sistema Cantareira. São José dos Campos, 2015.

DOURADO, F.; ARRAES, T.C. e SILVA, M.F. O Megadesastre da Região Serrana do Rio de Janeiro: as causas do evento, os mecanismos dos movimentos de massa e a distribuição espacial dos investimentos de reconstrução no pós-desastre. Anu. Inst. Geocienc. [online]. 2012, vol. 35, n.2, pp. 43-54. ISSN 0101-9759.

ERVATTI, L.R. Dinâmica Migratória no Estado do Rio de Janeiro na Década de 9o: Uma Análise Mesorregional. Dissertação de Mestrado. IBGE/ENCE. 2003.

FJP. Déficit habitacional no Brasil. Fundação João Pinheiro. Centro de Estatística e Informações Belo Horizonte, 2005.

FJP. Déficit habitacional municipal no Brasil 2010. Fundação João Pinheiro. Centro de Estatística e Informações - Belo Horizonte, 2013.

FREITAS, C.M. et al. Vulnerabilidade socioambiental, redução de riscos de desastres e construção da resiliência: lições do terremoto no Haiti e das chuvas fortes na Região Serrana, Brasil. Ciênc. saúde coletiva, Rio de Janeiro, v. 17, n. 6, June 2012.

Fudanção IBGE. Pesquisa de Informações Básicas Municipais - MUNIC, Rio de Janeiro, 2013. Fundação IBGE. Censo Demográfico 2010.

HOGAN, D.J.; MARANDOLA JR., E. Bringing a population-environment perspective to hazards research. Population and Environment, v. 34, p. 3-21, 2012. 
IPCC. Managing the Risks of Extreme Events and Disasters to Advance Climate Change Adaptation [FIELD, C.B.; V. BARROS, T.F. STOCKER, D. QIN, D.J. DOKKEN, K.L. EBI, M.D. MASTRANDREA, K.J. MACH, G.-K. PLATTNER, S.K. ALLEN, M. TIGNOR; P.M. MidGLEy (eds.)]. A Special Report of Working Groups I and II of the Intergovernmental Panel on Climate Change (IPCC). Cambridge University Press, Cambridge, UK, and New York, NY, USA, pp. 25-64. 2012.

JUNIOR, H.M. Desconcentração econômica e atratividade regional no estado do Rio de Janeiro entre 2000 e 2010. Cadernos do Desenvolvimento Fluminense, v. 1, p. 23-52, 2013.

LAVELL, A.; M. OPPENHEIMER; C. DIOP; J. HESS; R. LEMPERT; J. LI; R. MUIR-WOOD; S. MYEONG. Climate change: new dimensions in disaster risk, exposure, vulnerability, and resilience. In: Managing the Risks of Extreme Events and Disasters to Advance Climate Change Adaptation [FIELD, C.B.; V. BARROS, T.F. STOCKER, D. QIN, D.J. DOKKEN, K.L. EBI, M.D. MASTRANDREA, K.J. MACH, G.-K. PLATTNER, S.K. ALLEN, M. TIGNOR; P.M. MIDGLEY (eds.)]. A Special Report of Working Groups I and II of the Intergovernmental Panel on Climate Change (IPCC). Cambridge University Press, Cambridge, UK, and New York, NY, USA, pp. 25-64. 2012.

LICCO, E.A. Vulnerabilidade social e desastres naturais: uma análise preliminar sobre Petrópolis. Revista de Saúde, Meio Ambiente e Sustentabilidade, vol. 8, n. 1, 2013.

LOGUERCIO, J.F.C.; ZAMBONI, V. Estudo de caso do Bairro Viçoso Jardim em Niterói - RJ. In: Anais do VI Encontro Nacional da ANPPAS, Belém, 2012.

. Morro do Bumba, etnografando a transformação de uma paisagem sob múltiplos olhares: da invisibilidade à tradédia, uma página que não deve ser virada. Dissertação (Mestrado em Antropologia - UFF), Niterói, 2013.

MARANDOLA JR. Habitar em risco: mobilidade e vulnerabilidade na experiência metropolitana. 2008. 278f. Tese (Doutorado em Geografia) - Instituto de Geociências, Universidade Estadual de Campinas, Campinas, 2008.

; MARQUES, C.; DE PAULA, L.T.; BRAGA, L.C. Crescimento urbano e áreas de risco no litoral norte de São Paulo. Revista Brasileira de Estudos de População, ABEP, 2013.

MARQUES, C. População e Riscos às mudanças ambientais em zonas costeiras da Baixada Santista: um estudo sócio-demográfico sobre os municípios de Bertioga, Guarujá e São Vicente. Campinas: Dissertação de Mestrado. IFCH, Unicamp, 2010.

. Mudanças ambientais em zonas costeiras: populações e riscos. In: Álvaro de Oliveira

D’Antona; Roberto Luiz do Carmo. (Org.). Dinâmicas demográficas e Ambiente. 1ed.Campinas: NEPO/UNICAMP, 2011.

. Riscos ambientais na costa de São Paulo: o caso de Guarujá, Bertioga e Caraguatatuba. In: Julia S. Guivant; Pedro Roberto Jacobi. (Org.). Perspectivas ambientais: novos teóricos e novas agendas públicas. 1ed.: Annablume, 2012.

. Em busca da resiliência? Urbanização, ambiente e riscos em Santos (sP). Campinas: Tese de doutorado em Demografia. IFCH, UNICAMP, 2014.

MASKREY, A (org.). Los desastres no son naturales. La Red, 1993.

OJIMA, R.; MARANDOLA, E.J.; Indicadores e políticas públicas de adaptação às mudanças climáticas: vulnerabilidade, população e urbanização. Revista Brasileira de Ciências Ambientais, São Paulo, n. 18, p.16-24, 2010.

REIS, J.B.C.; CORDEIRO, T.L.; LOPES, E.S.S. Utilização do sistema de monitoramento e alerta de desastres naturais aplicado a situações de escorregamentos caso de Angra dos Reis. Em: XIV SIMPÓSIO BRASILEIRO DE GEOGRAFIA FÍSICA APLICADA, v. 1, 2011.

RIBEIRO, M.J. Sociologia dos desastres. In: Sociologia, n. ${ }^{\circ} 18$, pp.23-43, 1995.

SILVA, E.T. O Estado do Rio de Janeiro no Censo 2010. Observatório das Metrópoles, INCT/CNPq/ FAPERJ/CAPES, Rio de Janeiro, 2011.

SILVA, V.P. da. Desastre ambiental: Comunidade morro do Bumba em Niterói. Trabalho de Conclusão de Curso (Graduação em Serviço Social - Universidade Federal Fluminense, Escola de Serviço Social), Niterói, 2012.

UFSC - Universidade Federal de Santa Catarina, CEPED - Centro Universitário de Estudos e Pesquisas sobre Desastres. Atlas brasileiro de desastres naturais 1991 a 2012: volume Brasil. Florianópolis: CEPED-UFSC, $2013 \mathrm{a}$. 
UFSC - Universidade Federal de Santa Catarina, CEPED - Centro Universitário de Estudos e Pesquisas sobre Desastres. Atlas brasileiro de desastres naturais 1991 a 2012: volume Rio de Janeiro. Florianópolis: CEPED-UFSC, 2013 b.

UNISDR. Global Assessment Report on Disaster Risk Reduction: Risk and Poverty in a Changing Climate - Invest Today for a Safer Tomorrow. United Nations International Strategy for Disaster Reduction, Geneva, Switzerland, 2009, 207 pp.

VALÊNCIO, N. Da morte da Quimera à procura de Pégaso: a importância da interpretação sociológica na análise do fenômeno denominado desastre. In: VALENCIO, N.; SIENA, M.; MARCHEZINI, V.; GONÇALVES, J.C. (orgs.). Sociologia dos Desastres: construção, interfaces e perspectivas no Brasil. 1. ed. São Carlos: RiMa, 2009.

Para além do 'dia do desastre': o caso brasileiro (Coleção Ciências Sociais). Curitiba: Appris. 2012. v. 1. 227p.

WILCHES-CHAUX, G. La vulnerabilidad global. In: MASKREY, A (org.). Los desastres no son naturales. La Red, 1993.

YOUNG, C.E.F.; AGUIAR, C.; POSSAS, E. Perdas Econômicas dos Desastres Climáticos no Estado do Rio de Janeiro, 2001-2010. Cadernos do Desenvolvimento Fluminense. v.5, p.19-30, 2014. 